\title{
Are the Trade Related Intellectual Property Rights the Way for Development? A Precedence Investigation between Human Development Index and Index of Patent Rights
}

\author{
Christian Carvalho Ganzert, Beatriz Selan, Leonardo Augusto Amaral Terra \\ University of São Paulo, São Paulo, Brazil \\ Email: ganzert@usp.br, $\underline{\text { beatrizselan@gmail.com, leoterra@usp.br }}$
}

Received 24 February 2014; revised 23 March 2014; accepted 16 April 2014

Copyright $(2014$ by authors and Scientific Research Publishing Inc.

This work is licensed under the Creative Commons Attribution International License (CC BY).

http://creativecommons.org/licenses/by/4.0/

(c) (i) Open Access

\begin{abstract}
The main question, which leads this analysis, interrogates the existence of a causality relation between the human development index and Index of Patent Rights. It was decided to use a database whereas all units of the cross section have the same periods of time for human development index and Index of Patent Rights. This database covers 84 countries with the two indicators between 1975 and 2005. By the use of the Granger test, it was found that Index of Patent Rights does not temporally precede human development index, which indicates the veracity and, consequently, the corroboration of the idea of Trade Related Intellectual Property Rights should represent the interests of the richer countries' great corporations, and not the underdeveloped nations, as said in the statement of World Trade Organization.
\end{abstract}

Keywords

Human Development, Intellectual Property Rights, Innovation, Property Rights, International Trade

\section{Introduction}

The Index of Patent Rights (IPR) was developed by Ginarte and Park (1997) [1] and had its application reviewed in Park (2008), when the index was updated to 2005 and expanded from the original 110 countries to 
122. It has the objective to measure the level of patent rights protection of the analyzed countries, focusing on five issues: fields of coverage, membership in international treaties, duration of protection, enforcement mechanisms and restriction on patent rights [2]. In the presentation of his latest index upgrade, Park (2008) signalizes that the adoption of stronger patent laws varies by the level of economic development [2].

The United Nations Human Development Index (HDI) tries to measure the level of human development of 177 countries, by the use of a methodology which aggregates normalized measures of educational attainment, life expectancy, literacy and GDP per capita for each country. The HDI represents the average of the Life Expectancy Index (LEI), the Education Index (EI) and the GDP Index. The concept which bases the HDI idealization is the aim of several discussions around the choice of the three indices above. As created by the United Nations Development Program, the HDI should reflect the perspective of widening opportunities to persons in each of the analyzed countries [3], as the comparison among national human development potentials by the ranking of the HDI results.

The HDI is criticized because of its exclusive focus on national performance in the fields related to the indices which compose it. Furthermore, it is seen as a redundant measuring, concentrating its reasons on a kind of competition of welfare which does not fit the current point of view about human development, not paying attention to the global perspective. Other critic to the HDI relates to the ignorance of the issue ecology, once the improvement of inner indices like GDP could originate environmental damage, by the unsustainable production growth [4].

Even criticized, HDI is still the most important tool of measurement of national human development, and an enhanced device for the comparison among countries in three major categories: High, medium and Low Human Development Countries. Often, the top HDI ranked is the same top GDP index ranked. But, as Siggel (2005, p.2) shows,

High average income, even if distributed in a socially acceptable way, is not a guarantee of fulfillment of human needs in areas such as education, health care, longevity, or personal freedom. It has therefore become standard practice to define economic development by reference to sets of indicators measuring these aspects [5].

The concept of human development is normally used in consonance with the concept of economic development, even when the GDP per capita of a country has a negative correlation with life expectancy at birth, as in the cases of Brazil and Mexico. But, for most parts of the countries, the correlation between GDP per capita and health care indicators is highly positive, which created the idea of equality between these two issues [6]. But the economic development, granted by the growth of the national production, is only a mean to improve the people's lives - the final concern of the human development concept. This perspective copes with the Fukuda-Parr and Jahan definition, which says that "human development is simply defined as a process of enlarging choices" [7] —a definition that is attributed to Haq (1995) point of view [8]. That indicates the human development as the most representative concept of development, substituting the monolithic concept of the economic development as the main scale for the comparison among national states. That explains the importance that still attributed to HDI and its significance to the description of the geopolitical context.

Once the industrial production of the most economic developed countries is higher than that seen in the periphery of the capitalist system (or in those called undeveloped or developing countries), it is absolutely expected that the laws and treaties to protect the industrial patents find higher consolidation on them. But, it is not easy to establish a relation of causality between economic development and patent protection, once they are related on two ways: the more the access of the patent development is controlled, more incomes should be percept and more wealth is generated; furthermore, the more the economy of a nation is developed, the influence of its corporations is higher to assume a protectionist position of the legal institutions on the industrial patent issue. But, the concept of development is not limited to the economic issue [8], and other elements should influence the consolidation of patent rights legislation or, otherwise, be influenced by it. As the economic development level, the human development level can define the patent protection level, which makes the correlative analysis between the two indices, HDI and IPR possible.

The Human Development Report (HDR) from United Nations was released in the end of 2007, but its HDI rank was based on data collected until 2005. In December of 2008, a statistical update was released, without the accompanying of a report, with the coverage of the period up to 2006. As the last HDR, the data reported by Park (2008) were based on information related to the period up to 2005, which qualifies the comparison of the 
two indices, once they are based on the same time line analysis [2].

In conclusion, it is necessary to know which proposition is right: does the human development make the patent rights protections higher or does the protection of the patents rights improve the human development? This relation is the core of the HDI and IPR analysis concerned in this work. Looking for this answer, the main question which leads this analysis is the existence of a causality and precedence relations between the HDI and IPR, which necessarily passes by the perception of a high positive correlation between the two indexes.

\section{Patent Protection and Development: A Theoretical Overview}

As exposed by Lai (2008, p.1), "most technologies originate in the more-developed countries (normally, the North), making the pace of diffusion to the rest of the world a critical factor in the well-being of less-developed nations (the South)" [9]. But, some lines ahead, Lai (2008, p.1) admits that the technologies can only be used and diffused by the southern countries "only if the South's consumers can afford them" [9]. The perception about the deterministic development geopolitics is imported from the theories of Huntington (2001), the man who, in 1915, tried to create a relation between the geographic location of a nation and its development level [10], being quite criticized by the scientific community. Lai (2008) refers to the undeveloped countries as that sited on southern hemisphere, forgetting about Australia, for example [9]. Nowadays, it is part of the common sense of the scientific society the assumption that the configuration of the geopolitical framework of the economic development is a consequence of the historical processes of the expansion of capitalism, including its earlier ignition stage, the mercantilism. Therefore, the idea about the existence of a deterministic arrangement of the development process changed from the location of a nation in the geographic map to the level of its enrollment in the processes, which led to the consolidation of the industrialization.

It is evident that the countries which started first in the industrialization processes had the first contacts to its benefits-and costs [11]. In the other extreme, the countries that kept their economies based on the agricultural and primary products started to be more submitted to the political, military and economic power of those who entered first in the industrialism, the capitalism stage which was based on the industrial model. However, the submission had its deeper roots not in the industry rise, but in the cultural colonization started by the mercantilism [12]. The contemporary model of economic development, based on the importance of the technological capacity, can be seen as another kind of submission, the technological dependence [13].

For many authors, the fomentation of a national technological basis is one of the most effective ways to increase the economic expression of a country. In the cases of the underdeveloped countries, the technological development is seen as a hard but consistent way to reach the economic development. According to Carvalho (2002, p.1), "social welfare and economic growth depend, in part, on technological innovation" [14]. That is one of the arguments used by the World Trade Organization (WTO) to defend the implementation of the Trade Related Intellectual Property Rights (TRIPS) obligations for all the nations. As assume Braga, Fink and Sepulveda (2000, p.28), "in theory, patents could be set such than it would stimulate the development of new products and production processes at a socially optimal rate" [15]. Thereby, the patent rights protection is seen as a manner to qualify the countries included in the low developed group to acquire competitive advantages and improve their economic conditions.

But there is a complement to this theory which can be percept by the reading of Braga, Fink and Sepulveda (2000). The same authors concluded that the investments required from the initial research to the patent register are enormous, at least in the most part of the cases. And a good level of education and social development is required to provide native human resources to lead the researches, which should result in patent registers [15]. How can the poor countries compete with the rich ones beyond so many requirements based on the resources they do not have?

In the new stage of the capitalism, which earned the name of informationalism [16], the constant innovation is seen as plenty necessary. The globalization is a consequence of the communication intensification generated by the new information technologies. According to Griffin (2006, p.25), "ideas, information and knowledge are transmitted much more widely and more quickly". The revolution in communication opened the channels to the intensification of commerce and overseas investments. But, as the same author says, "trade barriers in general have fallen rapidly, but the process of trade liberalization has occurred much more slowly in products of special interest to poor countries" [17].

This happens because the rich countries try to protect their internal industries, blocking the access of their in- 
ternal costumers to the low technology products offered by the poor nations. As Moellendorf (2005, p.154) says, "the WTO's failure to eliminate the developed-world protectionism against underdeveloped countries is a clear case of injustice". If the economic undeveloped nations cannot deal their goods, just like the rich countries do, they will not percept the same vantages from the globalization process. Without the access to the free trade, that one which is propagated by the transnational capital, the poor countries have to find smarter ways to reach the necessary incomes to consolidate the needed resources for a future technology development [18]. This means that the inequity between rich and poor countries over the innovation prospection gets bigger, besides the time advantage the developed countries already have. As Griffin (2006, p.24) remembers, "the effort to create a global system of patent rights ignores the history and the fact that the now-rich countries copied freely the inventions of other countries during the early stages of their own development” [17].

In the front of this kind of affirmation, the idea of the patent rights protection as a way to help the economic development of the poor countries is quite hard to be valid, once they have a deep delay to overcome in the direction of the richer countries situation. This argument sounds as an inkling of the patent rights protection as a derivation of the consolidated economic development, and not a tool to reach it. Other concerns are related to the patent rights protection, as the moral implications around the pharmacological intellectual rights. One of the components of the DHI, the LEI, is directly related to the access of the people to the innovations of medicine science and the pharmacological industry.

A great part of the final costs of a medicament is dedicated to refund the investments made in the researches which propitiated its development. The patent rights are seen as mechanisms to ensure this repayment. According to Moellendorf (2005, p.153), "by granting monopoly-pricing power, patent regime provides incentives for original, inventive and innovative work". The constant technological advance depends on how much the companies and people involved in the sponsorship of the processes of technology development will earn for their intents [18]. Concerning to the moral implications of the profits expected by the investment in pharmacological and medical innovations, Moellendorf (2005) cites the declaration of the Sub-Commission on the Promotion and Protection of Human Rights of the United Nations:

Since the implementation of the TRIPS Agreement does not adequately reflect the fundamental nature and indivisibility of all human rights, including the right of everyone to enjoy the benefits of scientific progress and its applications, the right to health, the right to food and the right to self-determination, there are apparent conflicts between the intellectual property rights regime embodied in the TRIPS Agreement, on the one hand, and the international human rights law, on the other [19].

This position of the UN Sub-Commission of Human Rights is summed to the perception of Cook (2004, p.43), which says that "while patent rights are theoretically available to anyone, (...) they are still primarily a tool implemented by businesses and individual in wealthier nations for the protection of businesses and individuals in wealthier nations". This accedes with the thesis that the patent rights protection defenders arguments are strictly related to the necessity of the developed countries to keep its geopolitical economic position, on the contrary of the unsteady argument which classifies the patent protection as a legal device to guarantee the right to keep the competitive advantages of the innovative products originated in national level to leverage the economic and human development—specially in the underdeveloped world [20].

\section{Methodology: Panel Data and the Granger Causality Test}

The sample characteristics indicate that the most appropriate methodology is the panel data analysis, which has cross-sectional and time series dimensions. This is due mainly to monitoring different countries every quinquennium in order to match the data from the HDI index and data from international indicator of patent rights (IPR). Cameron and Trivedi (2005) define this methodology as a traditional application on individual data observed for certain periods of time. The same authors also claim that using this method improves the accuracy of the estimate, since it has greater amount of information over time, and allows the understanding of the behavior of countries over time, via the dynamics of individual behavior.

By incorporating some countries whose HDI values and IPR are irregular over time, which makes unavailable important data for previous years, it is an important task and allows the researchers efficiency gain. Therefore, it was decided to use a database whereas all units of the cross section have the same periods of time for HDI and IPR. This database covers 84 countries with the two indicators between 1975 and 2005, from an unbalanced da- 
tabase of 124 countries listed at United Nations HDI list. The conversion of an unbalanced panel in a balanced panel can generate large reduction in efficiency due to the loss of observations. It can also exacerbate potential problems of non-representativeness of the sample when the loss of randomness of data is not observed (Cameron \& Trivedi, 2005). Thus, this study does not fail to incorporate characteristics of countries that may be relevant to explain the relationship between human development of the country and the patent policies.

Usually the use of panel data methodology focused two main models: 1) fixed effect model, 2) random effect model. However, as the purpose here is only to test the causality between the indicators or the temporal precedence, it is proposed the analysis of Granger causality test for panel data. This type of causality was developed by Granger in 1969, originally for the context of prediction in time series, which was interpreted as a form of conditional independence or temporal precedence (Cameron \& Trivedi, 2005). As the definition of panel data also presents a facet of time series, it can be used in this study. However, it is not a causality investigation, but a precedence study.

Very broadly speaking, the test for causal relationship between international protection patent index and human development index in a panel context was conducted in two steps. First, the order of integration in the time series variables was tested using the unit-root tests. Second, having established the order of integration in the series, Granger causality was tested to understand the significance of the prediction and the relationship made by the series. This can provide some insightful suggestion about the precedence of the two series. Therefore, it is important to visualize the theoretical arguments among the unit-root tests used in the paper.

\section{Unit Root Tests: The Specifications of Panel Data}

One of the primary reasons for the use unit-root tests for panel data is to increase statistical power and to minimize the estimation of spurious regression by the conventional methodology. Costantini and Martini (2009) stated the complications with the use of panel data and the unit root process. The problems usually area associated to unobserved heterogeneity with cross section parameters and the difficulty to interpret the test results. Recently, the use of this method in panel data has increase, which leads to the development of two groups of unit root tests: common and individual unit root process.

The first set of tests assumes the existence of a common unit root process so that the parameters of persistence for each unit (or group) have the same autoregressive structure (AR (1)). The null hypothesis considered the integration order of each series of the panel as an AR (1), against the hypothesis that all series are stationary. Levin, Lin and Chu (2002) and Breitung (2000) are examples of this type of unit root tests.

Im, Pesaran and Shin (2003) and ADF-Fisher tests are the main unit root tests for the second group. They assume the existence of an individual unit root process as the parameters of persistence may vary freely for each group (or unit). Im, Pesaran and Shin (2003) test is based on the traditional augmented Dickey Fuller specification. That is, the null hypothesis assumes all series are non stationary while in the alternative hypothesis, at least one series is stationary.

These are the unit root tests used on the paper as first part of the estimation of temporal precedence amid human development index (HDI) and international indicator of patent rights (IPR). As mentioned before, this exercise is estimated firstly for the total group of countries and secondly for a balanced database. The second part of the estimation is verified by a Wald test that is used to capture the directional causality, if it is HDI that precedes IPR or if IPR precedes HDI.

For this, it is essential to determine the number of lags since the choice of a small number of lags can generate a specification bias and erroneous considerations. Therefore, the Granger causality was tested up to five lags and the choice for the best lag specification was made by selection the better results from the Akaike and Schwarz criterion.

Another point that should be addressed is the possibility of the database used on the study had some heteroskedasticity problems as well as serial correlation. In order to control these problems, that could affect the results presented on Granger causality tests, some procedures were considered. Tests were carried out to verify the presence of heteroskedasticity and serial correlation; however, the results showed that the series had no such problems.

\section{Estimation and Results of Granger Causality}

This section presents the details of the estimations made here as the unit root tests, choosing the time lag re- 
quired and Granger test itself. However, to provide an overview of the information, some descriptive statistics of variables HDI and IPR are presented in the table below (Table 1). The information is referent to 84 countries of the balanced database from 1975 to 2005.

The descriptive statistics from these two variables provided some insightful meanings to the association that can be related to them. For instance, the increase in human development indicator was followed by the extension of the indicator of protection through patents over the period analyzed. One sees a growth of approximately $20 \%$ of HDI in the last 30 years, but the growth rate associated with protection in the same period was nearly double the initial value, and may be more related to the participation of developed countries that may have greater weight in the use with patent rights compared to the others.

As a side note, the proportion of continents is really similar to the world proportion since Africa has $32 \%$ of the countries of the database, followed by Europe (22.6\%), Asia (18\%), Americas (25\%, 12\% from South America) and Oceania (2.4\%), as can be seen on Figure 1. Moreover, the strong participation of the IPR average in the 2000s does not necessarily represent broad-based growth for human development in the same period.

Based upon this data and the methodology provided above, one must test the existence of unit roots in both series (IPR and HDI), following the two sets of tests. Therefore, Table 2 and Table 3 show the results from the unit root tests conducted for this panel data for the HDI and IPR series, respectively. The main conclusion about them is that the database has two series that are stationary when one assumes a common unit root process (common effect for all countries), but the same conclusion is not possible to individual unit root process.

Table 1. Descriptive statistics from the variables among the years-balanced database.

\begin{tabular}{cccccccccc}
\hline \multirow{2}{*}{ Year } & \multicolumn{3}{c}{ HDI } & \multicolumn{3}{c}{ IPR } \\
\cline { 2 - 9 } & Mean & Std. Dev. & Min. & Max & Mean & Std. Dev. & Min. & Max \\
\hline 1975 & 0.622 & 0.195 & 0.246 & 0.883 & 1.829 & 0.687 & 0.588 & 3.825 \\
1980 & 0.648 & 0.189 & 0.264 & 0.895 & 2.010 & 0.818 & 0.588 & 4.350 \\
1985 & 0.669 & 0.184 & 0.261 & 0.911 & 2.087 & 0.891 & 0.588 & 4.675 \\
1990 & 0.689 & 0.184 & 0.279 & 0.931 & 2.186 & 0.995 & 0.588 & 4.675 \\
1995 & 0.708 & 0.187 & 0.296 & 0.938 & 2.734 & 1.068 & 1.075 & 4.875 \\
2000 & 0.725 & 0.187 & 0.321 & 0.958 & 3.214 & 0.990 & 1.275 & 4.875 \\
2005 & 0.741 & 0.186 & 0.370 & 0.968 & 3.478 & 0.823 & 1.783 & 4.875 \\
\hline
\end{tabular}

Source: elaborate by the authors given the database.



Source: prepared by the authors according to the database.

Figure 1. Country composition of the database according to continents from 1975 to 2005. 
Table 2. Statistics from the unit root tests for HDI.

\begin{tabular}{|c|c|c|c|c|c|c|}
\hline & \multicolumn{3}{|c|}{ Individual effects } & \multicolumn{3}{|c|}{ Individual effects and individual linear trend } \\
\hline & Statistic & Prob. & Obs. & Statistic & Prob. & Obs. \\
\hline \multicolumn{7}{|c|}{ Null: unit root (assumes common unit root process) } \\
\hline Levin, Lin \& Chu t & -7.94 & 0.000 & 294 & -6.29 & 0.000 & 186 \\
\hline Breitung t-stat & - & - & - & 5.25 & 1.000 & 135 \\
\hline \multicolumn{7}{|c|}{ Null: unit root (assumes individual unit root process) } \\
\hline Im, Pesaran and Shin W-stat & - & - & 294 & - & - & 186 \\
\hline ADF-Fisher Chi-square & 85.71 & 0.808 & 294 & 36.39 & 0.996 & 186 \\
\hline PP_Fisher Chi-square & 160.76 & 0.000 & 294 & 70.84 & 0.207 & 186 \\
\hline
\end{tabular}

Note: it was used the automatic selection of maximum lags and the automatic lag length selection based on SIC (which provide the lag zero as the best selection), Newey-West automatic bandwidth selection and Bartlett kernel was used as well and for each test we had balanced observations. Moreover, the probabilities for Fisher tests are computed using an asymptotic Chi-square distribution. All other tests assume asymptotic normality.

Table 3. Statistics from the unit root tests for IPR.

\begin{tabular}{|c|c|c|c|c|c|c|}
\hline & \multicolumn{3}{|c|}{ Individual effects } & \multicolumn{3}{|c|}{ Individual effects and individual linear trend } \\
\hline & Statistic & Prob. & Obs. & Statistic & Prob. & Obs. \\
\hline \multicolumn{7}{|c|}{ Null: unit root (assumes common unit root process) } \\
\hline Levin, Lin \& Chu t & 0.26 & 0.601 & 138 & -7.96 & 0.000 & 300 \\
\hline Breitung t-stat & - & - & - & 6.73 & 1.000 & 235 \\
\hline \multicolumn{7}{|c|}{ Null: unit root (assumes individual unit root process) } \\
\hline Im, Pesaran and Shin W-stat & - & - & 138 & - & - & 294 \\
\hline ADF_-Fisher Chi-square & 24.91 & 0.995 & 138 & 53.55 & 0.999 & 294 \\
\hline PP_Fisher Chi-square & 47.21 & 0.423 & 138 & 104.97 & 0.297 & 294 \\
\hline
\end{tabular}

Note: it was used the automatic selection of maximum lags and the automatic lag length selection based on SIC (which provide the lag zero as the best selection), Newey-West automatic bandwidth selection and Bartlett kernel was used as well and for each test we had balanced observations. Moreover, the probabilities for Fisher tests are computed using an asymptotic Chi-square distribution. All other tests assume asymptotic normality.

For the series of patent protection, there is the impossibility of rejecting the null hypothesis of unit root when it assumes both a common process for individual countries and an individual process. However, this only occurs when one considers the individual effects, i.e., when analyzing the non-presence of a linear trend in the estimation. When reviewing the two effects (presence of the intercept and linear trend), it is possible to reject the null hypothesis of unit root process with common, but it cannot reject the unit root hypothesis with individual process. This indicates that from the moment one considers that each country has its own intercept, the process is no longer stationary which may have implications for tests conducted with the series.

It is possible that by grouping different countries in the same sample, the unit root tests for individual processes (i.e., for each country) are difficult to reject the null hypothesis of the existence of a unit root process. However, when one analyzed the first difference of the process, one can see that the series has stationary characteristics, even when compared with the series level, which could indicate that the transformation of the stationary series in first difference would generate a moving average (MA) process.

It is important to remember that in the case of this database, when analyzing a lag of one period, this represents the effect in the previous five years, which makes the expansion of higher lags a difficult process since the database has a time restriction of starting in 1975. This indicates that, for lack of data, very long-term conclusions cannot be effectively addressed, since five lags represent thirty years in the database.

Therefore, the Granger causality tests conducted here consider up to five time lags for both null hypothesis that HDI does not Granger cause IPR as well as IPR does not Granger cause HDI. Table 4 below shows the 
Table 4. Results from Granger test: HDI does not Granger cause IPR.

\begin{tabular}{|c|c|c|c|c|c|c|}
\hline \multirow{2}{*}{ Lags } & \multicolumn{3}{|c|}{ Null: HDI does not Granger cause IPR } & \multicolumn{3}{|c|}{ Null: IPR does not Granger cause HDI } \\
\hline & Obs. & F-Statistic & Prob. & Obs. & F-Statistic & Prob. \\
\hline 1 & 504 & 32.1 & $* * *$ & 504 & 5.35 & ** \\
\hline 2 & 420 & 15.3 & *** & 420 & 0.71 & NS \\
\hline 3 & 336 & 14.9 & *** & 336 & 1.98 & NS \\
\hline 4 & 252 & 16.3 & $* * *$ & 252 & 0.82 & NS \\
\hline 5 & 168 & 6.3 & *** & 168 & 1.31 & NS \\
\hline
\end{tabular}

Note: ${ }^{*}$ significant at a $10 \%$ level; ${ }^{* *}$ significant at $5 \%$ level; ${ }^{* * *}$ significant at $1 \%$ level, NS is not significant.

values of the statistics of tests within the time lags, and the level of significance. The tests presented some interesting conclusion as the necessity to reject the null hypothesis of no causality in the Granger sense between HDI and IPR. That is, there must be some temporal precedence between the two series and HDI tends to precede IPR for the set of countries analyzed.

This initial finding is maintained in the long run, despite losing the intensity in the precedence over time. The point made here is that the best conditions for human development tend to have an important role in the choice of protection policies using patents in the future, which goes against the guidelines of United Nations.

For the null hypothesis of IPR does not temporal precede HDI, one can realize that the null hypothesis cannot be reject, which indicates the veracity and, consequently, the corroboration of statements made previously. However, in the short term (assuming a lag of one period, or five years), there is the possibility of simultaneity between the variables, making it more difficult to distinguish the effects. However, the effect provided by the precedence of IPR through HDI is of lesser intensity, which further confirms a possible precedence of human development for the adoption of protectionist policies.

\section{Final Remarks}

The results show that the WTO's TRIPS argument cannot be supported by the IPR and HDI empirical precedence analysis, once HDI precedes IPR, and not the inverse. It is more plausible to affirm that, once the country is already developed in all the internal components of the Human Development Index, the protection of patents will occur, on the contrary to TRIPS's arguments. Thus, Braga, Fink and Sepulveda (2000) seem to be wrong in their affirmations, because of the fails in their considered hypothesis [15].

At last, if the existence of a causal relation between HDI and IPR can be proved, it can only happens if HDI causes IPR, because the reversed way is not possible as proved by the method used in this research. Once it is said, the results support the Griffin (2006) idea [17], aligned with Cook (2004) [20], in which the TRIPS statement only represents the interests of great corporations, and not the underdeveloped nations' interests.

\section{References}

[1] Ginarte, J.C. and Park, W.G. (1997) Determinants of Patent Rights: A Cross-National Study. Research Policy, 1, 283301. http://dx.doi.org/10.1016/S0048-7333(97)00022-X

[2] Park, W.G. (2008) International Patent Protection: 1960-2005. Research Policy, 1, 761-766.

[3] Anand, S. and Sen, A.K. (1994) Human Development Index: Methodology and Measurement. Occasional Papers. New York: Human Development Report Office, United Nations. http://hdr.undp.org/en/media/HDI_methodology.pdf

[4] Sagar, A.D. and Najam, A. (1998) The Human Development Index: A Critical Review. Ecological Economics, 1, 249264. http://dx.doi.org/10.1016/S0921-8009(97)00168-7

[5] Siggel, E. (2005) Development Economics: A Policy Analysis Approach. Ashgate, New York.

[6] Sen, A.K. (1989) Development as Capability Expansion. In: Fukuda-Parr, S. and Shiva Kumar, A.K., Eds., Reading in Human Development, Oxford University Press, Oxford and New Delhi.

[7] Fukuda-parr, S. and Jahan, S. (2006) Haq Mahbub Ul (1934-1998). In: Clark, D., Org., The Elgar Companion to Development Studies, Edward Elgar, New York. 
[8] Haq, M. (1995) Reflections on Human Development. Oxford University Press, Oxford and New York.

[9] Lai, E. (2008) Intellectual Property Protection in a Globalizing Era. Economic Letter-Insights from the Federal Reserve Bank of Dallas, 3.

[10] Huntington, E. (2001) Civilization and Climate. Minerva Group, New York.

[11] Hobsbawn, E.J. (1962) The Age of Revolution. Signet, New York.

[12] Magnusson, L. (1995) Mercantilism: The Shaping of an Economic Language. Routledge, New York.

[13] Cooper, C. (1973) Science, Technology and Development: The Political Economy of Technical Advance in Underdeveloped Countries. Routledge, New York.

[14] De Carvalho, N.P. (2002) The TRIPS Regime of Patent Rights. Kluwer Law International, London.

[15] Braga, C.A.P., Fink, C. and Sepulveda, C.P. (2000) Intellectual Property Rights and Economic Development. World Bank, New York.

[16] Castells, M. (2000) The Rise of the Network Society: Economy, Society and Culture. Blackwell, New York.

[17] Griffin, K.B. (2006) A Witness of Two Revolutions. In: Boyce, J.K., et al., Orgs., Human Development in the Era of Globalization: Essays in Honor of Keith B. Griffin, Edward Elgar, New York.

[18] Moellendorf, D. (2005) The World Trade Organization and Egalitarian Justice. In: Barry, C. and Pogge, T.W.M., Eds., Global Institutions and Responsibilities: Achieving Global Justice, Blackwell, New York.

[19] UNHCHR (2000) Sub-Commission on Human Rights Resolution 2000/7. Office of the United Nations High Commissioner for Human Rights, Geneva. http://www.unhchr.ch/Huridocda/Huridoca.nsf/0/c462b62cf8a07b13c12569700046704e?Opendocument

[20] Cook, C. (2004) Patents, Profits \& Power: How Intellectual Property Rules the Global Economy. Kogan Page, New York. 


\section{Appendix}

Chart A1. Countries from the balanced database.

\begin{tabular}{|c|c|c|}
\hline Algeria & Honduras & Paraguay \\
\hline Argentina & Hong Kong, China (SAR) & Peru \\
\hline Australia & Hungary & Philippines \\
\hline Austria & Iceland & Portugal \\
\hline Bangladesh & India & Rwanda \\
\hline Belgium & Iran (Islamic Republic of) & Senegal \\
\hline Benin & Ireland & South Africa \\
\hline Bolivia & Israel & Spain \\
\hline Botswana & Italy & Sri Lanka \\
\hline Brazil & Jamaica & Swaziland \\
\hline Burkina Faso & Japan & Sweden \\
\hline Burundi & Kenya & Switzerland \\
\hline Cameroon & Korea (Republic of) & Syrian Arab Republic \\
\hline Canada & Luxembourg & Thailand \\
\hline Central African Republic & Madagascar & Togo \\
\hline Chad & Malawi & Trinidad and Tobago \\
\hline Chile & Malaysia & Tunisia \\
\hline Colombia & Malta & Turkey \\
\hline Congo & Mauritania & United Kingdom \\
\hline Costa Rica & Mexico & United States \\
\hline Denmark & Morocco & Uruguay \\
\hline Dominican Republic & Nepal & Venezuela \\
\hline Egypt & Netherlands & Zambia \\
\hline El Salvador & New Zealand & Zimbabwe \\
\hline Finland & Nicaragua & \\
\hline France & Niger & \\
\hline Ghana & Nigeria & \\
\hline Greece & Norway & \\
\hline Guatemala & Pakistan & \\
\hline Guyana & Panama & \\
\hline
\end{tabular}

